\title{
Key Determinants of Enterprise E-banking Assimilation
}

\author{
Ziqi Liao \\ School of Business \\ Hong Kong Baptist University \\ Kowloon, Hong Kong \\ Email: victor@hkbu.edu.hk \\ Xinping Shi \\ School of Business \\ Hong Kong Baptist University \\ Kowloon, Hong Kong \\ Email: xpshi@hkbu.edu.hk \\ Man Hei Yee \\ School of Business \\ Hong Kong Baptist University \\ Kowloon, Hong Kong \\ Email: mhryee@gmail.com
}

\begin{abstract}
This paper empirically examines key determinants of enterprise e-banking assimilation. The analytical results unveil that utilitarian value and usability positively affect trustworthiness and satisfaction of enterprise e-banking services. In particular, firms' satisfaction possesses a significant mediating effect on continuance intention to use enterprise e-banking services in business operations. The present study makes contributes to research and practice. The empirical findings enrich the understanding of enterprise e-banking assimilation and have managerial implications for the development of enterprise e-banking systems and services.
\end{abstract}

Keywords Enterprise e-banking, systems, services, assimilation, firms

\section{Introduction}

The commercial banks have been developing online banking services and utilizing electronic channels to deliver banking and financial information, enhance customer services, and reduce transaction costs. In general, the banks provide enterprises and consumers with online banking services respectively, because of different service requirements. As an important form of business-to-business services, enterprise e-banking refers to the online banking services that the commercial banks offer to firms in different industries, which include import and export document application, employee payroll, bill payment, fund transfer, and commercial loan services. As a matter of fact, enterprise e-banking services play an important role in facilitating firms to deal with banking tasks and transactions in relation to business operations. This paper aims at deepening the understanding of enterprise ebanking assimilation. Therefore, a conceptual model and several hypotheses are proposed to articulate the relationships between key determinants and enterprise e-banking continuance intention along the lines of the technology acceptance model (Davis et al., 1989) and e-service quality (Parasuraman et al., 2005), the theory of reasoned action (Fishbein \& Ajzen, 1975; Ajzen \& Fishbein, 1980), and the theory of planned behaviour (Ajzen, 1985, 1991). In addition, we carry out a survey to gather data from firms and test our conceptual model and hypotheses. The empirically-grounded findings to be presented in the following sections not only validate the causal effects and relationships of the constructs in the conceptual model, but also have implications for enhancing enterprise e-banking services. This paper includes the construction of a conceptual model in the next section. Thereafter, it explains the research methods and presents the empirical results. It then discusses the findings together with the theoretical and practical implications. Lastly, the paper is concluded by summarizing the findings and providing suggestions for future research.

\section{Conceptual Model and Hypotheses}

The present study empirically examines enterprise e-banking assimilation by extending the theoretical underpinnings of technology acceptance model (Davis et al., 1989) and e-service quality (Parasuraman et al., 2005). The theory of reasoned action (Fishbein and Ajzen, 1975; Ajzen and Fishbein, 1980) and 
the theory of planned behaviour (Ajzen, 1985, 1991) are also applied to explain firm users' continuance intention to use enterprise e-banking systems and services. The theory of bounded rationality suggests that it is imperative to concentrate on a core subset of variables in evaluation of technology-based systems and services (Simon, 1972). Thus, we design a conceptual model, in which trustworthiness, utilitarian value, and usability are assumed to be antecedents that respectively affect firms' satisfaction with enterprise e-banking, while utilitarian value and usability may influence trustworthiness. At the same time, firms' satisfaction is assumed to mediate the relationships between the three antecedents and continuance intention to use enterprise e-banking. In particular, trustworthiness refers to the extent to which firm users perceive that the commercial banks have ability, integrity, and benevolence in provision of enterprise e-banking services (Mayer et al., 1995; Colquitt et al., 2007; Porter and Donthu, 2008), while utilitarian value and usability are respectively derived from perceived usefulness and perceived ease of use in the technology acceptance model. In line with the reasoning of Oliver $(1997,1999)$ and Parasuraman et al. (2005), firms' satisfaction refers to the extent to which firm users are satisfied with enterprise e-banking services, while continuance intention refers to firm users' willingness to repeatedly use enterprise e-banking services. The conceptual model aims at articulating the extent to which firms' satisfaction has a mediating effect on relationships between the antecedents and firms' continuance intention to use enterprise e-banking services.

\subsection{Trustworthiness}

It is meaningful to examine the trustworthiness of enterprise e-banking as it indicates the extent to which firm users perceive that the commercial banks can provide trustworthy enterprise e-banking services. In line with the theoretical underpinnings of trustworthiness (Mayer et al., 1995; Colquitt et al., 2007), this study articulates trustworthiness with regard to ability, integrity, and benevolence in enterprise e-banking service processes. It is imperative for the commercial banks to responsibly offer high quality e-banking services and fulfil meet clients' needs in order to make firm users be satisfied with the relevant services (Parasuraman et al., 2005). In addition to the development of e-banking systems, the commercial banks are expected to possess the expertise in the operations of enterprise ebanking services. In particular, the banks should be capable of providing enterprise e-banking services and tackling online transactions problems. The banks should also be fair to their firm clients when they perform transactions through enterprise e-banking systems. Moreover, the banks should quickly respond to service requests from firm clients and benevolently care about their interests and concerns throughout the service processes. The service providers with established trust usually do not behave opportunistically or take advantages of their customers in the service processes (Porter and Donthu, 2008). However, it is not uncommon that some users may feel that online services may involve risks, because they do not have direct face-to-face communication with service staff (Yousafzai et al., 2005). The banks need to consistently maintain and deliver trustworthy online banking and financial services to enhance firm users' satisfaction with enterprise e-banking. Therefore, we propose Hypothesis 1.

H1. Trustworthiness positively affects firms' satisfaction with enterprise e-banking services.

\subsection{Utilitarian Value}

In this study, utilitarian value is defined as the extent to which firm users perceive that enterprise ebanking can effectively and efficiently process payments and other banking activities in association with business transactions, which is conceptually consistent with perceived usefulness (Davis et al., 1989; Liao and Cheung, 2002, 2008; Liao and Wong, 2008; Luo et al., 2010; Changchit et al., 2017). The enterprise e-banking systems should enable firm users to perform banking activities and minimize costs and workload of relevant processes through the Internet. As using the enterprise e-banking is task-oriented, firm users should be rational in decision making when they utilize enterprise e-banking services. As a matter of fact, the functionalities of e-banking services for firms are relatively more complex than those for individual consumers. The enterprise e-banking systems should serve as an important platform, through which the commercial banks can effectively provide business clients with professional and trustworthy banking services. Apart from reliably managing accounts and processing transactions data, the enterprise e-banking systems must efficiently accomplish enterprise banking activities, streamline cash flows, and improve operational efficiency of business transactions. It is therefore imperative for enterprise e-banking services to possess utilitarian value which may enhance trustworthiness and business clients' satisfaction with the relevant online banking services (Porter and Donthu, 2008). Generalizing from these observations, we propose the following hypotheses.

H2a. Utilitarian value positively affects trustworthiness of enterprise e-banking services.

H2b. Utilitarian value positively affects firms' satisfaction with enterprise e-banking services. 


\subsection{Usability}

In the present work, usability refers to the extent to which enterprise e-banking can be easily used to handle banking tasks in association with business operations, which is related to user experience in terms of ease of use (Davis et al., 1989; Liao and Cheung, 2002, 2008; Changchit et al., 2017). With regard to e-banking, the websites of a commercial bank serve as a platform for providing consumers and enterprises with online banking services, on which there are different logins that respectively enable consumers and companies to access e-banking services. Previous studies suggest that perceived ease of use or usability has an effect on consumers' behavioural intention to use e-banking (Kazi, 2013) and attitudes towards mobile banking (Changchit et al., 2017). In the case of enterprise e-banking, it is important to examine the effect of usability, as firm users may need to work on relatively complicated transactions such as import and export businesses, which are different from the banking activities of individual consumers. However, in practice, some users may not appreciate the functionalities of the enterprise e-banking systems. Thus, it is desirable that enterprise e-banking systems can facilitate firm users to easily use the relevant functions to perform banking tasks and process business transactions. The commercial banks should design and build user-friendly enterprise e-banking systems in order to enhance the trustworthiness of e-banking and enable users to gain satisfactory experience from online banking services (Porter and Donthu, 2008). Therefore, we propose the following hypotheses.

H3a. Usability positively affects trustworthiness of enterprise e-banking services.

H3b. Usability positively affects firms' satisfaction with enterprise e-banking services.

\subsection{Mediating Effect of Satisfaction}

The present conceptual model aims at articulating the extent to which firms' satisfaction mediates the effects of such antecedents as utilitarian value, usability and trustworthiness on continuance intention to use enterprise e-banking services. In line with Oliver (1997, 1999), satisfaction is a summary of psychological state resulting from prior feelings and experiences, which has a positive effect on continuance intention ( $\mathrm{Li}$ and $\mathrm{Liu}, 2014$ ). Firms are enterprise customers of the commercial banks. The firm users should possess rational attitudes towards the implementation and use of enterprise ebanking in dealing with the relevant banking jobs for their companies. Thus, in the present work, the psychological sense of customer satisfaction is adapted to define the construct of firms' satisfaction as the extent to which firms are satisfied with present enterprise e-banking services that are provided by the commercial banks. It is expected that firms' satisfaction can positively convey the effects of such antecedents as trustworthiness, utilitarian value, and usability on continuance intention to use enterprise e-banking. Actually, firm users of enterprise e-banking are task-oriented in the processes of managing cash flows and handling financial matters in relation to business operations for their companies. Therefore, the theoretical underpinnings of reasoned action and planned behaviour (Ajzen and Fishbein, 1980; Ajzen, 1985, 1991) can be appropriately applied to explain firm users' behaviour in association with the assimilation of enterprise e-banking. The effect of satisfaction on continuance intention has been explored in different online services (Wang and Du, 2014; Joo et al., 2017). With regard to enterprise e-banking services, it is meaningful to find out whether firm users feel that their expectations are fulfilled through testing the mediating effect of satisfaction. Generalizing from the above observations, we propose Hypothesis 4.

H4. Satisfaction mediates the effects of trustworthiness, utilitarian value, and usability on continuance intention to use enterprise e-banking services.

\section{Method}

We designed a preliminary questionnaire consisting of multiple question items to operationalize each of the constructs in the conceptual model. The question items or observable variables in relation to each construct were in line with the measurements in the existing literature. A seven-point Likert scale ranging from 1 'strongly disagree' to 7 'strongly agree' was used to obtain respondents' assessments of the relevant question items. In addition, the questionnaire included some items to obtain demographic data. As most managers in local small firms are Chinese speakers, they might feel more comfortable in responding to survey questions in Chinese. We translated the English version questionnaire to Chinese version. A backward translation of Chinese questions to English was also performed to ensure that the meanings of the relevant questions were consistent. Therefore, we formulated a bilingual version of the questionnaire. Meanwhile, we conducted a pilot study by requesting eight managers from different firms to review the preliminary version of the questionnaire. These managers offered constructive suggestions for improving the question items, since they were knowledgeable in business operations and had experiences in enterprise e-banking services. In line with the feedback obtained from the pilot 
study, we refined and finalized the questionnaire for survey. Thereafter, we carried out a survey to gather empirical data from firms in different industries such as trading, manufacturing, and financial services. In the survey process, the questionnaire together with a cover letter and returned envelop was delivered to over one thousand enterprises. The survey resulted in the collection of one hundred and forty three questionnaires returned from responding firms that had less than fifty employees. The respondents included firm owners, partners, and managers having experiences in enterprise e-banking services. They responded to our survey and completed the questionnaire on behalf of their firms.

\section{Results}

We systematically test the survey data gathered from the responding firms using the AMOS software. In line with the analytical procedures suggested by Anderson and Gerbing (1988), Byrne (2010), and Hair et al. (2010), we examine the measurement model and conduct hypothesis testing.

\subsection{Measurement Model}

We test the internal consistency reliability of the measurement model. The test results show that the Cronbach's alpha $(\alpha)$ values are $0.87,0.75,0.86,0.94$, and 0.90 and the composite reliability (CR) values are $0.90,0.83,0.90,0.96$, and 0.94 , respectively, which suggest that the measurement items are retained and the internal consistency reliability of the measurement model is justified (Hair et al., 2010). In addition, we test the construct validity in terms of convergent validity and discriminant validity. First, convergent validity indicates the extent to which the indicators or observable variables of a construct converge or share a considerable proportion of variance (Bagozzi et al., 1991; Hair et al., 2010). The measurement items of the constructs have loadings that are greater than the threshold (Hair et al., 2010), which suggest that the relevant observable variables are loaded onto a respective manifested construct. The average variance extracted (AVE) values of the five constructs are 0.65 , $0.57,0.65,0.84$, and 0.84 , respectively. These AVE values are greater than the threshold suggested by Hair et al. (2010). The test results indicate that the convergent validity of the constructs in the conceptual model is justified. Second, discriminant validity indicates the extent to which a construct is distinct from the other constructs (Hair et al., 2010), which provides evidence that a unique construct can capture the propensity of the represented concept. It is assessed by comparing the square root of the AVE of a construct with the correlation coefficients between the tested construct and the other constructs. The values of the square root of AVE are greater than the correlation coefficients of the corresponding pairs of relevant constructs. Therefore, the discriminant validity of each of the constructs in the conceptual model is justified. Moreover, the test of multicollinearity results in variance inflation factors (VIF) ranging from 1.5 to 2.0, which are less than the suggested threshold of 10.0 (Hair et al, 2010). The test results show that there is no multicollinearity. Thus, the constructs are independent facets that represent different aspects of enterprise e-banking assimilation. Lastly, the confirmatory factor analysis (CFA) results in a series of indices such as $\chi^{2}=343.674, \mathrm{df}=177, \chi^{2} / \mathrm{df}=$ $1.942, \mathrm{NFI}=0.863, \mathrm{IFI}=0.928, \mathrm{TLI}=0.914, \mathrm{CFI}=0.927$, and RMSEA $=0.079$, which indicate that the measurement model significantly fits.

\subsection{Model Analysis and Hypothesis Testing}

We use the structural equation modelling to estimate path coefficients of the conceptual model $\left(\mathrm{M}_{\mathrm{o}}\right)$ and to test the hypotheses. As shown in Table 1, the test results indicate the goodness of fit of $\mathrm{M}_{\mathrm{o}}\left(\mathrm{X}^{2}=\right.$ $\left.352.895, \mathrm{df}=196, \chi^{2} / \mathrm{df}=1.961, \mathrm{NFI}=0.859, \mathrm{IFI}=0.926, \mathrm{TLI}=0.912, \mathrm{CFI}=0.925, \mathrm{RMSEA}=0.079\right)$. In particular, we apply the mediating model analysis procedure and competing model approach to examine alternate models in search of the best parsimonious model (Baron and Kenny, 1986; Anderson and Gerbing, 1988; Hair et al., 2010) and test whether there is another model with better goodness of fit index and explanatory power. Thus, we suggest three alternate models $\left(\mathrm{M}_{1}, \mathrm{M}_{2}\right.$, and $\left.\mathrm{M}_{3}\right)$ on the basis of the conceptual model $\left(\mathrm{M}_{\mathrm{o}}\right)$ by adding a path from each of the two exogenous constructs such as utilitarian value and usability to the endogenous construct of continuance intention. In comparison with $\mathrm{M}_{\mathrm{o}}, \mathrm{M}_{1}$ has an additional path from utilitarian value to continuance intention, while $\mathrm{M}_{2}$ has an additional path from usability to continuance intention. In addition, $\mathrm{M}_{3}$ is constructed by connecting both utilitarian value and usability to continuance intention. The three alternate models are tested by comparing $\chi^{2}$ differences, goodness-of-fit indices, and p-values. Table 1 shows that the coefficients and $t$-values of the additional paths are insignificant in the three alternate models $\left(M_{1}, M_{2}\right.$, and $\mathrm{M}_{3}$ ), which indicate that either utilitarian value or usability has little direct effect on continuance intention. Therefore, $M_{o}$ is an appropriate model to unveil the mediating effect of firms' satisfaction. 


\begin{tabular}{|c|c|c|c|c|c|c|c|c|}
\hline \multirow[b]{2}{*}{ Path } & \multicolumn{2}{|l|}{$\mathrm{M}_{\mathrm{o}}$} & \multicolumn{2}{|l|}{$\mathrm{M}_{1}$} & \multicolumn{2}{|l|}{$\mathrm{M}_{2}$} & \multicolumn{2}{|l|}{$\mathrm{M}_{3}$} \\
\hline & Coefficients & t-value & Coefficients & t-value & Coefficients & t-value & Coefficients & t-value \\
\hline $\mathrm{UV} \Rightarrow \mathrm{TR}$ & 0.276 * & 2.463 & $0.254 *$ & 2.278 & $0.277^{*}$ & 2.467 & $0.255^{*}$ & 2.290 \\
\hline $\mathrm{UV} \Rightarrow \mathrm{SAT}$ & $0.425 * *$ & 4.148 & $0.406^{* *}$ & 4.004 & $0.426 * *$ & 4.132 & $0.407^{* *}$ & 4.003 \\
\hline $\mathrm{US} \Rightarrow \mathrm{TR}$ & $0.565^{* *}$ & 4.928 & $0.580 * *$ & 5.036 & $0.563^{* *}$ & 4.911 & $0.579 * *$ & 5.029 \\
\hline $\mathrm{US} \Rightarrow \mathrm{SAT}$ & $0.323^{* *}$ & 3.129 & $0.318 * *$ & 3.034 & $0.318 * *$ & 3.367 & $0.316^{* *}$ & 3.010 \\
\hline $\mathrm{TR} \Rightarrow \mathrm{SAT}$ & $0.228 *$ & 2.211 & $0.250 *$ & 2.429 & $0.231^{*}$ & 2.238 & $0.251 *$ & 2.437 \\
\hline $\mathrm{SAT} \Rightarrow \mathrm{CI}$ & $0.778 * *$ & 10.884 & $0.664^{* *}$ & 5.221 & $0.748 * *$ & 6.264 & $0.648 * *$ & 4.282 \\
\hline $\mathrm{M}_{1}: \mathrm{UV} \Rightarrow \mathrm{CI}$ & & & 0.139 & 0.288 & & & & \\
\hline $\mathrm{M}_{2}: \mathrm{US} \Rightarrow \mathrm{CI}$ & & & & & 0.036 & 0.756 & & \\
\hline $\mathrm{M}_{3}: \mathrm{UV} \Rightarrow \mathrm{CI}$ & & & & & & & 0.135 & 1.029 \\
\hline $\mathrm{M}_{3}: \mathrm{US} \Rightarrow \mathrm{CI}$ & & & & & & & 0.022 & 0.193 \\
\hline$\chi^{2}$ & 352.895 & & 351.159 & & 352.802 & & 351.859 & \\
\hline$\hat{\mathrm{df}}$ & 180 & & 179 & & 179 & & 178 & \\
\hline$\chi^{2} / \mathrm{df}$ & 1.961 & & 1.966 & & 1.971 & & 1.977 & \\
\hline$\Delta \chi^{2}$ & & & 1.700 & & 0.091 & & 1.036 & \\
\hline NFI & 0.859 & & 0.859 & & 0.859 & & 0.859 & \\
\hline IFI & 0.926 & & 0.926 & & 0.925 & & 0.925 & \\
\hline TLI & 0.912 & & 0.912 & & 0.911 & & 0.911 & \\
\hline CFI & 0.925 & & 0.925 & & 0.924 & & 0.924 & \\
\hline RMSEA & 0.079 & & 0.080 & & 0.080 & & 0.080 & \\
\hline
\end{tabular}

Notes: UV = Utilitarian Value; US = Usability; TR = Trustworthiness; SAT $=$ Satisfaction; $\mathrm{CI}=$ Continuance intention; NFI = normed fit index; IFI = incremental fit index; TLI $=$ Tucker-Lewis coefficient; CFI $=$ comparative fit index; RMSEA $=$ root mean squared error of approximation; $\Delta \chi^{2}=\left(\chi^{2}{ }_{0}-\chi^{2}, i=1,2,3\right) ;{ }^{*} p<0.01 ; * * * 0.001$

Table 1. Analytical results of structural equation modelling

\section{Discussion}

The present empirical analysis results in meaningful findings and implications. First, the support of H1 suggests that trustworthiness significantly and positively influences firms' satisfaction with enterprise e-banking services. In addition, the empirical justifications of $\mathrm{H}_{2} \mathrm{a}, \mathrm{H} 2 \mathrm{~b}, \mathrm{H} 3 \mathrm{a}$, and $\mathrm{H}_{3} \mathrm{~b}$ suggest that utilitarian value and usability have significant and positive effects on the trustworthiness of enterprise e-banking and firms' satisfaction with enterprise e-banking services. Moreover, the empirical support of $\mathrm{H}_{4}$ indicates that firms' satisfaction significantly mediates the effects of trustworthiness, utilitarian value, and usability on continuance intention to use enterprise e-banking services. The results suggest that trustworthiness, utilitarian value, and usability are key attributes of enterprise e-banking services. The firms tend to continually use online banking systems and services that can effectively help them manage financial matters, streamline cash flows, and reduce transactions costs in business operations.

This study makes contributions to research. The present empirical findings deepen the understanding of enterprise e-banking assimilation and enrich the knowledge of online business-to-business services. Given that small firms represent an important customer segment of the commercial banks, enterprise e-banking serves as a key distribution channel of banking services to these companies. Therefore, it is worthwhile to explore the mechanism that underlines the firms' adoption of enterprise e-banking. This study focuses on such a promising topic and extends the theoretical underpinnings of technology acceptance and e-service quality to elucidate such a technology-based service setting. It strives for advancing the present knowledge by operationalizing the relevant constructs in relation to enterprise e-banking. The present findings justify that the underpinnings of technology adoption and electronic service quality can be blended to examine the assimilation of enterprise e-banking services in the context of small firms. It has also been found that the theory of reasoned action and the theory of planned behaviour can be appropriately applied to explain firm users' behaviour in association with the use of enterprise e-banking services, because they use the relevant services in a planned and rational manner to accomplish business operations. The present empirical results rationalize that as key determinants of enterprise e-banking assimilation, utilitarian value, usability, and trustworthiness positively influence firms' satisfaction which in turn significantly mediates the relationships between these determinants and continuance intention to use enterprise e-banking. In summary, utilitarian value, usability, and trustworthiness of enterprise e-banking collectively explain firms' satisfaction with enterprise e-banking services. In particular, firms' satisfaction serves as an important mediator that conveys the effects and explanatory powers of the three key determinants on enterprise e-banking continuance intention. Therefore, the present empirical work lays a foundation for future research in relation to enterprise e-banking and other service innovations in different contexts. 
In addition, the present study makes contributions to practice. The empirical findings have managerial implications for the development of enterprise e-banking services. The banks should further develop the enterprise e-banking systems that have more useful and user-friendly functionalities to effectively support firms' business operations. The banks should also devote to enhance the trustworthiness of enterprise e-banking services with regard to ability, integrity, and benevolence, since trustworthiness considerably affects firms' satisfaction. Moreover, the banks should efficiently respond to service requests from firm clients and quickly handle service interruptions and hidden transaction fees, as these matters may affect e-banking service quality and make firms cease using enterprise e-banking services. Lastly, it is imperative to establish and develop sustainable business relationships between the commercial banks and their firm clients. In practice, the firms are suggested to streamline banking tasks in association with business operations and pay attention to user training in order to efficiently use enterprise e-banking. The commercial banks are also suggested to collaboratively work with firm clients in the processes of online banking services. For instance, the banks may offer firm users some training in relation to the operations and information security of enterprise e-banking. Therefore, firm users have a better understanding of enterprise e-banking systems and innovative financial services.

\section{Conclusion}

The present study empirically justifies the relationships of antecedents and consequences of enterprise e-banking assimilation in small firms. The analytical results unveil that trustworthiness, utilitarian value, and usability positively and significantly influence firms' satisfaction and continuance intention, while satisfaction mediates the relationships between these determinants and continuance intention to use enterprise e-banking services. It has been found that the relevant theoretical underpinnings can be blended to build a conceptual model for examining enterprise e-banking assimilation. In addition, the theory of reasoned action and the theory of planned behaviour can be usefully applied to explain firm users' behaviour in association with the use of enterprise e-banking services, as they possess rational attitudes towards the technology-based service innovations. The present work makes contributions to research and practice. The empirically-grounded findings deepen the understanding of enterprise ebanking assimilation and provide managerial insights for improving enterprise e-banking services and implementing advanced information and communications technologies in service operations. Lastly, future research may explore relevant attributes in a particular context to identify the extent to which the improvement of different aspects can encourage firms to use enterprise e-banking services.

\section{References}

Ajzen, I. 1985. "From Intentions to Actions: A Theory of Planned Behavior," in J. Kuhl and J. Beckmann, eds. Action-Control: From Cognition to Behavior. Heidelberg: Springer.

Ajzen, I. 1991. "The Theory of Planned Behavior: Some Unresolved Issues,” Organizational Behavior and Human Decision Process (50:2), pp. 179-211.

Ajzen, I., and Fishbein, M. 1980. Understanding Attitudes and Predicting Social Behavior. Englewood Cliffs, NJ: Prentice-Hall.

Anderson, J.C., and Gerbing, D.W. 1988. "Structural Equation Modeling in Practice: A Review and Recommended Two-step Approach," Psychological Bulletin (103:3), pp. 411-423.

Bagozzi, R.P., Yi, Y., and Phillips, L.W. 1991. "Assessing Construct Validity in Organizational Research," Administrative Science Quarterly (36:1), pp. 421-458.

Baron, R.M., and Kenny, D.A. 1986. "The Moderator-mediator Variable Distinction in Social Psychological Research: Conceptual, Strategic, and Statistical Considerations," Journal of Personality and Social Psychology (51), pp. 1173-1182.

Byrne, B.M. 2010. Structural Equation Modeling with AMOS: Basic Concepts, Applications, and Programming. Second edition, New York: Routledge, Taylor and Francis Group.

Changchit, C., Lonkani, R., and Sampet, J. 2017. "Mobile Banking: Exploring Determinants of Its Adoption," Journal of Organizational Computing and Electronic Commerce (27:3), pp. 239261.

Colquitt, J.A., Scott, B.A., and LePine, J.A. 2007. "Trust, Trustworthiness, and Trust Propensity: A Meta-analysis Test of Their Unique Relationships with Risk Taking and Job Performance," Journal of Applied Psychology (92), pp. 909-927. 
Davis, F.D., Bagozzi, R.P., and Warshaw, P.R. 1989. "User Acceptance of Computer Technology: A Comparison of Two Theoretical Models," Management Science (35:8), pp. 982-1003.

Fishbein, M., and Ajzen, I. 1975. Belief, Attitude, Intention and Behavior: An Introduction to Theory and Research. Reading, MA: Addison-Wesley.

Hair, J. F., Black, W.C., Babin, B.J., and Anderson, R.E. 2010. Multivariate Data Analysis: A Global Perspective. Seventh edition, New Jersey: Pearson Prentice Hall.

Joo, Y.J., Park, S., and Shin E.K. 2017. “Students' Expectation, Satisfaction, and Continuance Intention to Use Digital Textbooks," Computers in Human Behavior (69), pp. 83-90.

Kazi, A.K. 2013. "An Empirical Study of Factors Influencing Adoption of Internet Banking among Students of Higher Education: Evidence from Pakistan," International Journal of Finance and Banking Studies (2:2), pp. 87-99.

Liao, Z., and Cheung, M.T. 2002. "Internet-based E-banking and Consumer Attitudes: An Empirical Study," Information \& Management (39:4), pp. 283-295.

Liao, Z., and Cheung, M.T. 2008. "Measuring Consumer Satisfaction in Internet Banking: A Core Framework," Communications of the ACM (51:4), pp. 47-51.

Liao, Z., and Wong, W.K. 2008. "The Determinants of Customer Interactions with Internet-enabled Ebanking Services," Journal of the Operational Research Society (59:9), pp. 1201-1210.

Luo, X., Gurung, A., and Shim, J.P. 2010. "Understanding the Determinants of User Acceptance of Enterprise Instant Messaging: An Empirical Study," Journal of Organizational Computing and Electronic Commerce (20:2), pp. 155-181.

Mayer, R.C., Davis, J.H., and Schoorman, F.D. 1995. "An Integrative Model of Organizational Trust," Academy of Management Review (20:3), pp. 709-734.

Oliver, R.L. 1997. Satisfaction: A Behavioural Perspective on the Consumer. New York: McGraw-Hill.

Oliver, R.L. 1999. “Whence Customer Loyalty?” Journal of Marketing (63:4), pp. 33-44.

Parasuraman, A., Zeithaml, V.A., and Malhotra, A. 2005. "E-S-QUAL: A Multiple-item Scale for Assessing Electronic Service Quality," Journal of Service Research (7:3), pp. 213-233.

Porter, C.E., and Donthu, N. 2008. "Cultivating Trust and Harvesting Value in Virtual Communities," Management Science (54), pp. 113-128.

Simon, H. 1972. "Theories of Bounded Rationality," in C. McGuire and R. Radner, eds. Decision and Organization, Amsterdam: North Holland Publishing Company.

Wang, R.B., and Du, C.T. 2014. "Mobile Social Network Sites as Innovative Pedagogical Tools: Factors and Mechanism Affecting Students' Continuance Intention on Use," Journal of Computers in Education (1:4), pp. 353-370.

Yousafzai, S.Y., Pallister, J.G., and Foxall, G.R. 2005. "Strategies for Building and Communicating Trust in Electronic Banking: A Field Experiment," Psychology and Marketing (22:2), pp. 181201.

\section{Copyright}

Copyright: (C) 2018 authors. This is an open-access article distributed under the terms of the Creative Commons Attribution-NonCommercial 3.0 Australia License, which permits non-commercial use, distribution, and reproduction in any medium, provided the original authors and ACIS are credited. 